\title{
Shifting Concepts of Autonomy in the Hong Kong Hospital Authority
}

\author{
Janice Caulfield • Agnes Liu
}

Published online: 14 September 2006

(C) Springer Science + Business Media, LLC 2006

\begin{abstract}
The Hong Kong Hospital Authority is the main provider of public health care services in Hong Kong. It operates 41 public hospitals, 74 general out-patient clinics and 45 specialist out-patient clinics. This article examines the reason for its establishment as a statutory body in 1990 and offers an assessment of its success in meeting the goals of the reformers. A belief that health care service delivery would be improved is largely supported by the evidence, but this may have more to do with budget and policy consistency than management autonomy and flexibility. Statutory independence, with its promise of improved efficiency, has its limits in the highly complex field of health where there are multiple players and where professional autonomy remains a key claim. In recent times, the authority has been subject to several reform attempts and, together with the SARS epidemic in 2003, these have had a significant impact on its organizational structure and practices, in particular, on its degrees of autonomy.
\end{abstract}

Keywords Statutory authority · Autonomy - Integration ·

Health care $\cdot$ Hospital authority

\section{Introduction}

The Hong Kong Hospital Authority (HA) was established in 1990 as a statutory body to take responsibility from the then Medical and Health Department for the management of public hospitals. The HA has since been the main provider of public healthcare services in Hong Kong. At present, it operates 41 public hospitals, 74 general out-patient clinics, and 45 specialist out-patient clinics (HMDAC, 2005: 5). Since its establishment, the HA has been subject to several reform attempts and these, together with the Severe Acute Respiratory Syndrome (SARS) epidemic in

J. Caulfield $(\bowtie) \cdot$ A. Liu

Department of Politics and Public Administration, University of Hong Kong,

Hong Kong, China 
2003, have had a significant impact on its organizational structure and practices which have challenged its autonomy.

While "autonomy" and its opposite "integration" have both been seen as virtues in the study of public administration, few would argue that they are absolute values. Autonomy may lead to dynamic self-governance, but may also produce isolation (Thynne \& Wettenhall, 2004). Similarly, integration may involve cooperative interaction, but may also entail subjugation. Statutory bodies often have to balance the need for autonomy against a need for integration. Yet autonomy and integration may co-exist within the same organization. For example, an organization may be closely supervised by the government but immune from pressure exerted by interest groups, or vice versa. There remains a tension between these values. Thompson, Snape, and Stokes (1999) argue that central budgetary control may compromise effective delivery of services. Coupled with decentralized management and a measurement system which gives priority to efficiency over effectiveness, this can lead to under-funding and a financial crisis (Pollitt, 1986; Thompson et al., 1999).

This article traces the life of an autonomous public statutory body, exploring periods of organizational change in terms of these competing values. The article addresses three main questions:

- Given the size and complexity of the HA, in what aspects has the Authority experienced autonomy and in what other aspects has it undergone integration?

- Insofar as autonomy and integration are in tension, how has this dynamic been played out over the course of the HA's life; that is, has it moved further in one direction than the other?

- If autonomy can lead to both positive and negative consequences, how are these to be interpreted, in the case of the HA, as benefits to the public?

The article first explores the rationale for establishing the HA as an incorporated statutory body. Second, as the concepts of autonomy and integration are only relevant vis-à-vis other agents, the HA's external and internal relationships for the last 15 years are traced. Hopefully, this review can provide some insights into the questions posed above, but also more generally contribute to an understanding of the nature of statutory bodies.

\section{Mixed Motives for Corporatization?}

Prior to the establishment of the HA, health services were provided by the Medical and Health Department which managed two groups of public hospitals: government hospitals whose employees were civil servants, and subvented hospitals run by voluntary organizations. The government of the day, however, saw a number of problems with this system, such as over-centralization, inflexibility, archaic management structure, low staff morale, lack of courtesy to patients, long waiting lists, over-crowded conditions, poor coordination between government and subvented hospitals, and a lack of public participation in hospital management (Yuen, 1994: 167). In 1979, the government conducted a review of the department and recommended a regionalized structure and the streamlining of the central administration (Gauld \& Gould, 2002). A failure to implement the recommendations 
fully led eventually to the Scott inquiry, a commissioned team of Australian consultants. The Scott Report (1985) recommended an independent hospital authority to take responsibility for all public hospitals. Further, the government proposed corporatization, claiming it would solve the many extant problems by providing:

- Greater flexibility in personnel matters such as salary, hiring and firing, employment of part-time staff, and permitting hospital doctors to undertake private practice;

- Greater public participation through membership on the HA board and its committees;

- Greater incentives through financial devolution and management independence at the HA and hospital levels (Yuen, 1994: 167).

In the words of the former Secretary for Health and Welfare, Dr. Yeoh, the objectives were to "improve the efficiency and effectiveness of hospital services through the introduction of a new corporate culture and scientific management" (Yeoh, 2001: 167).

Corporatization was thus underpinned by notions of decentralization and autonomy, but integration also played a role. Although voluntary hospitals were heavily subsidized, they were autonomous in that they were governed by an independent board of directors which made important policy and expenditure decisions, and were responsible for their own human resource management (HRM) matters (Gauld \& Gould, 2002; Thompson et al., 1999). The 15 government hospitals and 23 subvented hospitals were governed by different regulations. The former were overcrowded, while the latter were under-utilized. Standards of service provided were hence uneven. The first HA Chairman, Sir Chung Sze-yuen, believed that one of his tasks was "moulding (the government and subvented hospitals) into one system" (South China Morning Post, 7 January 1993). Therefore, in addition to the management and participatory rationales for corporatization, it was believed that a better integration of government and subvented hospitals would lead to a more efficient allocation of resources, as well as higher staff morale by bringing remuneration for the subvented sector in line with their civil service counterparts (Yuen, 1994: 167). An agreement signed between the HA and subvented hospitals in May 1991 signified such an integration.

\section{The Hospital Authority and the Health, Welfare and Food Bureau}

The HA is accountable to the government through the Secretary for Health, Welfare and Food. The secretary, in turn, is responsible for the formulation of health policies and for the monitoring of the HA's performance (HA, 2005; Legislative Council Select Committee, 2004: 233). From the bureau's perspective, the HA enjoys autonomy in the control and management of its hospitals and institutions (Yeoh, 2001). No approval is needed from the bureau for matters on hospital operations, such as temporary curtailment of hospital services, transfer or diversion of patients among hospitals, and closure of hospital wards or service departments. Yet the HA must inform the Health, Welfare and Food Bureau (HWFB) of, or seek its advice on, major decisions on hospital operations that could have substantial impact on the 
provision of hospital services for the public (Legislative Council, 2005: 234). On policy matters, Gauld (1998) has observed that the HA has, since its establishment, assumed the role of a "policy machine". It has produced numerous documents containing key initiatives for health services development, changes to the structure of hospital-based services, and visions for the future, thereby surpassing its strictly operational role but acting in accordance with its mandate to "function as if it were a private organization striving for continual improvement in performance" (Gauld, 1998: 70). Indeed, the informational capacity of the authority exceeds that of the bureau and health policy debate and service development emanates from the HA rather than the bureau. Despite these blurred roles and responsibilities, it has been suggested that the government is unlikely to regain control given the massive amount of information that the HA possesses and the corporate image and strategy that it has built up since its establishment (Gauld, 1998; Gauld \& Gould, 2002).

It was perhaps not surprising that one of the reports on the SARS noted that the respective roles of the HA board, the HA chief executive and the secretary were not always clear, and that there was no distinct delineation of role or authority prior to the SARS outbreak (HA Review Panel, 2003: 128). This led the legislator representing the medical sector ${ }^{1}$ to suggest that the government regain control over the HA by appointing the bureau secretary as chairman of the board (Lee \& Benitez, 2003a). Concern about role confusion had already surfaced in an Audit Commission Report in 2001 which criticized the bureau for not exercising adequate monitoring over the HA's purchase of medical equipment. The HA was required to submit a list of proposed equipment purchases with estimated costs to the bureau for approval. Any variations would require separate approval. However, the Audit Commission found that a list of proposed equipment (and estimated costs) had been prepared for only one of three hospital projects that the HA was then undertaking. It recommended the preparation of a comprehensive list to facilitate bureau monitoring of expenditure. In response, the bureau and the authority both argued the impracticality of lists because of the rapid development in medical technology (Audit Commission Report, 2001: 18). Indeed, the bureau showed deference to the HA in claiming to "accept the professional views of the HA" on matters of expenditure (Hon, 2001).

\section{The Hospital Authority and the Department of Health}

As a first stage toward corporatization, the government announced in 1989 that the Medical and Health Department would be split into two new departments. The Department of Health would be responsible for all public health matters such as health education, monitoring and preventive programs, and the operation of outpatient clinics. The Hospital Services Department would manage government and subvented hospitals. The latter was expected to be an interim measure and its tasks would be transferred to the HA once all staff opted for the new terms of employment (Gauld \& Gould, 2002: 61-65).

\footnotetext{
${ }^{1}$ Functional constituencies, in which legislators represent particular sectors or occupations, are a part of Hong Kong's electoral system.
} 
The HA quickly took as its first objective the creation of a "seamless health care system" and articulated its corporate vision thus: "The Hospital Authority will lead in collaborating with other health care providers and carers in the community to create a seamless health care system which will maximize health care benefits and meet community expectations" (cited in Holliday \& Tam, 2000). However, it has been pointed out that what the HA was actually striving for was the domination and macro-coordination of the health sector requiring other service providers to accept it as the sovereign power. There was little consensus between the HA and the Department of Health about their relationship. For example, hospitals (managed by the HA) and out-patient clinics (managed by the department) tended to off-load patients onto one another, and there was no formal referral system between the two. Consensus as to their respective responsibilities could not be reached because of different resource allocations and the costs of collaboration (Gauld, 1998: 73).

In March 2000, the government considered transferring the 64 general out-patient clinics operated by the department to either the HA or the private sector. A transfer would allegedly achieve cost-effectiveness and clarify the role of the department as regulator rather than the service provider of clinics. The dilemma for the government was that transferring clinics to the HA would provide the public with a one-stop service from general to specialist consultations, but would increase the burden on the authority; and that, while contracting out clinics to private doctors would improve efficiency through competition, it might raise concerns of service quality (Lee, 2000a, b). In December 2000, the government in its consultation document entitled "Lifelong Investment in Health" proposed that the department's out-patient services be transferred to the HA to achieve better integration of primary and secondary medical care. The proposal was implemented and the clinics were transferred to the HA in phases between 2001 and 2003 (HWFB, 2004: 5-6).

The effectiveness of the reform was tested by the unexpected SARS outbreak in March 2003. In assuming responsibility for the clinics, the HA also assumed responsibility for the health of the entire population (primary care) and not merely that of patients. Such responsibility would require more effective coordination with the department. During the epidemic, departmental representatives sat on the HA's Working Group on SARS, sent staff to assist with managing an outbreak at one of the HA hospitals, developed the e-SARS system with the HA, co-ordinated specimen sharing in its public health laboratories, and issued infection control guidelines to healthcare workers.

The HA was subsequently criticized for not maintaining adequate co-operation with the department. While both issued guidelines to homes for the elderly, their advice on infection control measures differed. Further, both initially maintained separate SARS databases, leading to a failure to exchange of information on suspected cases in real time (SARS Expert Committee, 2003: 116). The HA had the power under its Ordinance to close any part of a hospital. However, the Quarantine and Prevention of Disease Ordinance gives authority to control and prevent infectious disease to the department. It was thus considered undesirable that the HA make the decision to close and reopen a ward in one of its hospitals without involving the department. SARS thereby drew attention to the problem of extant statutory powers, and role and task confusion embedded in organizational reform. Calls have since been made for a review of each body's respective roles and 
responsibilities, while one member of the SARS Expert Committee even urged the government to consider merging them (Legislative Council, 2005: 246, Lee \& Benitez, 2003a, b).

\section{The Hospital Authority Board and the Management Executives}

The HA Ordinance provides that members to the HA board are appointed by the chief executive of the HKSAR. The board is responsible for formulating policies and monitoring executive performance with members sitting on various functional subcommittees (HA, 2003/2004). ${ }^{2}$ The chief executive of the HA reports to the HA board and its chairman (Legislative Council, 2005). The board is in turn accountable to the government through the bureau (Gauld, 1998). There are 27 board members, of whom 23 are non-public officers, three are public officers representing the bureau, the department, and the Financial Services and Treasury Bureau, and one principal officer who is the HA's chief executive. Seven out of the 27 members, including the chairman and the chief executive, are medical doctors. None of them is remunerated as members, except the chief executive (HA, 2003/2004). A 1999 study found that hospital chief executives and members of the hospital governing committees felt that the board was not performing the tasks they considered important (Hayllar, 1999). Further, lay representation on the board and functional committees was seen merely as a form of window-dressing. A more positive view, however, was that the board and committees could serve the useful purpose of raising the community's and patients' concerns (Scott, 2005).

Delegation (or abrogation) of decision-making power from the board to management executives was most evident during the SARS crisis. At a special meeting called in April 2003, the board Chairman, Dr Leong, decided to lead a Task Force comprising all board members to oversee the management of the epidemic and report to the bureau secretary (Legislative Council Select Committee, 2004). Despite this, the board was bypassed when operational decisions were made between the HA and the bureau. The chief executive decided if and when to involve the board. The potential closure of one of the hospitals, for example, did not involve the board in discussions. Nor did the HA ask for the board's permission to bypass normal procedures for procurement. Moreover, the bureau secretary issued instructions to the chief executive without involving the board (HA Review Panel, 2003: 129, 147). Not only was power delegated down from board to management, but it was also delegated up by board members, as a collective, to the chairman. It was later found that the board was only informed of developments through Dr Leong who explained that "Board members had given me the trust and mandate as they felt this would be the best way out" (Legislative Council Select Committee, 2004: 243).

\footnotetext{
${ }^{2}$ There are altogether eleven committees: Planning Committee, Audit Committee, Staff Committee, Supporting Services Development Committee, Human Resources Committee, Main Tender Board, Finance Committee, Public Complaints Committee, Medical Services Development Committee, Staff Appeals Committee and Emergency Executive Committee which will only be activated in emergency states (HA, 2005). 
One board member commented that the board was a "rubber stamp". While denying this allegation, Dr Leong nonetheless admitted that "since most Board members are 'lay persons' ... they felt that the best way was to let the executives concentrate on fighting the battle" (Legislative Council Select Committee, 2004: 240-241). It was also suggested that the size of the board was not conducive to rapid decision-making during a crisis (HA Review Panel, 2003: 126). In the end, the board was criticized for failing to monitor the executives and make important decisions, in spite of the community's expectation that it would do so. It was said that, while $\mathrm{Dr}$ Leong seemed to have acted on behalf of the board, there was no clear and proper procedure for the board to authorize him to do so (Legislative Council Select Committee, 2004: 247). Overall, this unclear chain of command resulted in poor decisions and confusion (HA Review Panel, 2003: 129). One solution subsequently proposed, but not accepted by the government, was that the chief executive should also serve as board chairman (Lau, 2004).

\section{The Hospital Authority Head Office and Constituent Hospitals}

The HA's role is to provide its constituent hospitals with support services and policy guidance through constant contacts with the hospital chief executives (HCEs), allowing for each hospital to operate independently. At the outset, the HA appointed the HCEs from within the hospitals, typically doctors with little management experience. Thus, the HA had to involve itself heavily in the training of HCEs, thereby exercising influence over the overall shape of the new system. As the HCEs became more confident, they began to question the dominant role played by the HA, which seemed to them to have threatened hospital independence. Seemingly straightforward proposals over planning, expenditure and personnel had to be approved by the HA head office, a laborious process preventing the HCEs from developing innovative practices. There remained confusion about which decisions the HCEs could make without the HA's endorsement, and there were conflicting messages from the several directors within head office. Moreover, the HCEs considered the HA to be out of touch with frontline provision of hospital services, as its senior management lacked practical experience in hospital procedures. It has been suggested the HA's reluctance to decentralize operational decision-making to individual hospitals reflected its authoritarian and paternalistic mentality (Gauld, 1998: 62-72).

Centralized approaches to operational policy were gradually replaced by a more decentralized approach. The HA moved to confine itself to policy formulation, leaving the task of policy interpretation, as well as recruitment, selection and staff development, to the hospitals. Thompson et al. (1999) found that a majority of line managers felt they were given more power in staff training and development, performance appraisal and staff communication, though not in determining pay and staffing levels or mixes. Yet there remained criticisms that decentralization was superficial and that the HA still controlled operations. Hospital HR managers, for example, admitted turning often to the HA head office for policy interpretation, and also to feelings of dependency generally combined with a lack of management time and skills, compounded by the HA's tight control over hospital budgets. 
Surprisingly, the SARS crisis pointed to a rather different picture. It was found that there was no clear line of authority from the HA head office to the hospital HR managers. Decisions on deployment were made by individual hospitals rather than by the HA; there was poor coordination of volunteers; staff were deployed as individuals rather than in teams; there were varying methods of selecting staff to work in SARS areas; a lack of a clear policy on rotation in and out of the SARS wards; there was no register of training and experience of key staff and no contingency plans for manpower deployment. Together, these added to a picture of inconsistencies and coordination failure. One of the SARS reports observed that "there did not appear to be any discernible plan of action from the HA head office ... Frontline staff were making decisions left, right and centre as the crisis developed ..." (HA Review Panel, 2003: 170). A lack of control and coordination by the HA in maintaining consistent treatment of staff across the organization, and undesirable recruitment competition among hospitals, had even been observed prior to the SARS crisis (Thompson et al., 1999).

In financial control, the relationship between the authority and its constituent hospitals is likewise ambivalent. Although each hospital has its own finance department responsible for making decisions on utilization of resources by frontline units, the HA remains centralized through resource controls which take the form of various plans, statements, reports, cost centres, targets, indicators, assessments and audits (Cheung, 2003). Individual hospitals thus appear to act simply as agents pledging service targets in exchange for budget allocations. According to the then bureau secretary, financial management was to be devolved from the HA to individual hospitals. The HA would play a supporting role by providing guidance, policies and procedures, resource management tools, methodologies, and benchmark information (Yeoh, 2001). Indeed, the Audit Commission found that most hospitals had set up their own procurement sections to purchase medical equipment and selected their own contractors for providing maintenance services without central control and coordination. The Audit Commission (2001: 32-33, 51) considered this to be unsatisfactory as it led to duplication of expenditure and effort, lower bulk-purchase discounts, and a proliferation of medical equipment performing similar functions. It thus recommended a central procurement and maintenance unit be established to reduce costs and ensure consistent performance standards among hospitals.

\section{Relations among Individual Hospitals: The Cluster Concept}

Under the HA Ordinance, individual hospitals are seen as entities independent of one another, and such a system tends to create competition for resources. However, the HA's intent was to foster collaboration and, towards this end, it adopted the cluster concept whereby public hospitals are grouped together into clusters of one acute tertiary hospital and five or six smaller satellite hospitals serving a broad population area. ${ }^{3}$ Despite this early initiative, there was in fact little cooperation among hospitals as most of them wished to establish themselves as key service providers,

\footnotetext{
${ }^{3}$ At present, HA hospitals are grouped into seven clusters: Hong Kong East, Hong Kong West, Kowloon Central, Kowloon East, Kowloon West, New Territories East and New Territories West (HA, 2005). 
leading to an inefficient allocation of resources and even duplication or oversupply of services within and across clusters. The distribution of beds and human resources, for example, was found to favor Hong Kong Island (Gauld, 1998). In the most recent consultation document entitled "Building a Healthy Tomorrow" released in July 2005 , it is stated that the number of accident and emergency (A\&E) attendances and proportions of truly emergency cases varied greatly among public hospitals. Also, acute and convalescent bed provisions ranged from under one to over 10 per 1,000 population in different districts. The HA was urged to identify the need for merging the various A\&E departments in an attempt to improve efficiency and achieve economies of scale (HMDAC, 2005: 30-33).

Inefficient resource allocation is also seen in the procurement of medical equipment. The HA grants a lump sum to hospitals each year for the purchase of minor medical equipment, based on their scale of operations. In 2001/2002, 29 hospitals were each given $\$ 0.5$ million or less, whereas 12 major hospitals were each allocated \$1.5 million to \$4 million. The Audit Commission (2001: 23-24) considered this undesirable as some hospitals might, because of contingencies, need more than the amount allocated, whereas there might be no need for others to utilize fully the funds given to them. It therefore suggested that the HA allocate resources for minor medical equipment on the basis of clusters to allow for more flexibility to hospitals in the same cluster. A year later, the HA announced it would consider merging or consolidating services and even hospitals. Such a move was said to be a natural progression of the cluster concept (Benitez, 2002).

Nonetheless, public hospitals continued to suffer from coordination problems. This was most evident during the SARS outbreak. Individual hospitals competed for protective equipment for their staff, and there was no uniform policy on infectioncontrol measures. The legislator representing the medical constituency claimed there was "serious compartmentalization" within the HA and said that managers of different hospitals and clusters should give up their "warlord" mentality (Moy \& Lee, 2003). In their defence, the HA chief executive pointed out that during the crisis the seven cluster chief executives met with HA directors every morning. The cluster system, he claimed, enabled hospitals in the same cluster to support one another (Lee, 2003). Yet this was not supported by the findings of the HA's own panel on SARS. The panel noted that staff were confused by contradictory messages and instructions coming from the head office, clusters and individual hospitals. Some found it difficult to pass on information to the top management in the HA because of the extra layer of management at the cluster level (HA Review Panel, 2003: 129130). It was further claimed that the cluster concept had diluted hospital-level autonomy and made the HA's structure even more hierarchical (Cheung, 2003). By 2004, the board chairman conceded that there was a need for better coordination and policy-making at the top (Lee, 2004).

Others have argued for more centralized control and better integration. A public doctors' group said that, while the cluster concept did facilitate the sharing of patient workload and treatment experiences within the same cluster, there was no mechanism to provide relief when one cluster was over-burdened. Cooperation between clusters was based on a friendly relationship but not on the actual capability of the cluster. As there was no central commander to make the final decision, some hospitals "fell like dominoes". A legislator also argued that, while decentralization of 
management to clusters might work well in peace time, the HA should centralize control during a crisis (HA Review Panel, 2003: 130).

\section{The Hospital Authority and the Private Sector}

One of the HA's missions is to collaborate with other agencies and bodies in the healthcare field to provide the greatest benefit to the local community (HA, 2003/ 2004). In reality, it has assumed a position of dominance rather than cooperation. Prior to the establishment of the HA, only those who could not afford medical services would go to public hospitals. After the HA was formed, the public returned to the public hospitals because of their improved services and much lower fees compared with the private sector. It was predicted that the HA's monopoly was likely to continue and competitors would gradually be edged out (Gauld, 1998). During the SARS outbreak, it was noted that the HA was reluctant to transfer patients to the private sector lest they lose patients to it, while private practitioners had to compete with the HA for limited supplies of protective equipment. Also, it was said that private doctors and hospitals offered their help in treating non-SARS cases, but they felt that their capacity was not fully utilized and their dedication in maintaining services during the epidemic not sufficiently recognized (SARS Expert Committee, 2003: 108, 151).

At the outset, the HA appeared to adopt the same reluctance in contracting out its services. As early as 1993, it was suggested in an HA internal paper that its specialist out-patient clinics be contracted out in order to shorten the long waiting lists. However, the HA stated that "it is only a concept, not a serious suggestion". The paper contained no concrete plan or details on how this could be done (Wan, 1993). Two years later, the HA similarly down-played a call to contract out eye surgery to the private sector, saying that a major obstacle was the matter of charges (Wiseman, 1995). Later, the government commissioned a team of specialists from Harvard University to conduct a review of the healthcare sector. In their report, submitted in 1999, it was claimed that the system was highly compartmentalized with "thick walls" separating the public and private sectors which resulted in duplication of services and a discontinuity of health care. The Harvard team suggested a "competitive integrated" healthcare system in which the HA would be broken down into 12 to 18 regional health integrated systems that could contract with private general practitioners and specialists (Legislative Council, 2005: 3-4). However, Dr Leong, who later became the HA chairman, objected to merging the HA with the private sector, saying that the two could not supplement each other and there would neither be checks and balances nor choices for patients upon merger (Parwani \& Lam Wan, 1999). Likewise, Dr William Ho, who later became the HA chief executive, said that if hospitals competed with one another, patients' interests might be sacrificed for financial considerations (Lam Wan, 1999). ${ }^{4}$

Recent years have witnessed a change in the HA's attitude towards contracting out and competition. In 2001, the HA said it was considering contracting out some

${ }^{4}$ For a fuller discussion of the Harvard Report, see Holliday and Tam, 2000. 
services to create a better balance between the private and public sectors because it could no longer afford to provide primary care for all patients. Also, it would use its out-patient clinics as training grounds for family doctors and invite private family doctors to serve as part-time trainers (Moy, 2001a, b). In 2003, the HA planned to expand private wards to generate income which would result in competition with private hospitals (Benitez, 2003). In 2004, the HA again stated that it would outsource some public clinics and, indeed, had already allowed some public doctors to practice in private clinics in order to promote public-private interaction $(\mathrm{Wu}$, 2004). This change of attitude by the HA towards a public-private interface reflected a change in broader government policies.

In 2000, the government decided to transfer the general out-patient clinics run by the Department of Health to the HA rather than to the private sector, a move criticized by some legislators who claimed this would marginalize the HA as improved service quality would attract more patients to public clinics. Indeed, the specter of a creeping "nationalized health service" appeared at the center of these objections (Benitez, 2001). In the consultation document on healthcare reform released in the same year, the government acknowledged a public-private imbalance, but conceded there was no quick and easy solution to the problem given the huge price differences. The government made it clear that it did not wish to interfere with fees and charges of public and private hospitals (Legislative Council, 2005: 8). Instead, it merely encouraged the HA to collaborate with the private sector over standards, protocols and information-sharing. Hence, the 2000 reform proposal did not seriously attempt to challenge the HA's monopoly of the healthcare sector (Gauld \& Gould, 2002).

A change in the government's attitude was witnessed in the latest consultation document released in July 2005. It stated that the public and private sectors should go beyond collaboration and cooperation. There should be "integration and healthy competition" instead of pre-dominance by either of them. The HA was urged to purchase some primary medical care services from the private sector and to hire private doctors experienced in tertiary services to practice in public hospitals on a part-time basis when there was a shortage of such skills. Public hospitals were also encouraged to operate more shared-care programs in which the public and private sectors were each responsible for one part of a patient's treatment. One of the HA clusters is operating such a program in its provision of obstetric care services. Finally, the government promised to review the fees and charges of A\&E services, specialist out-patient services, and the drug supply of public hospitals to reduce the price difference between the public and private sectors (HMDAC, 2005).

\section{The Hospital Authority and the Community: Professional Autonomy}

One of the HA's missions is to encourage community participation in the system and to be more directly accountable to the public (HA, 2003/2004). The HA has long maintained an internal accountability system. In 1996, the HA devised a set of audit codes that enabled hospital managers to monitor what drugs individual doctors had been giving their patients and to seek explanations from them for prescribing certain drugs. Some doctors resisted, arguing this would put pressure on them not to 
prescribe expensive drugs even if they were in the best interests of their patients, thereby eroding their clinical autonomy (Tacey, 1996). The following year, the HA proposed expanding the membership and jurisdiction of its Public Complaints Committee (PCC). The PCC would include independent experts and would investigate not only general complaints but also those on medical care and those with legal implications (Moir, 1997). Two years later, the PCC planned to open its meetings selectively and to publicize findings of its investigations (Chan, 1999). ${ }^{5}$ However, the PCC continued to conduct its hearings in camera so that even the complainants were not allowed to attend. Only brief reports to the HA board were made every 6 months. The HA said it wanted to maintain the committee hearing as an internal inquiry process (Lee, 2000a, b).

In 2001, the HA disciplined a surgeon for answering a telephone call while performing an operation. After the Medical Council found the surgeon innocent of misconduct, the Hong Kong Medical Association and the Public Doctors' Association demanded the HA reverse its own disciplinary decision (Gauld \& Gould, 2002: 112). Nonetheless, the HA proceeded to propose setting up a team of independent medical auditors composed of doctors and nurses from overseas or local private hospitals to monitor the performance of its surgeons and to report directly to the HA chief executive. This was intended to replace the old system of in-house assessments, although the auditors' reports would not be made public (Moy, 2001a). Some doctors argued that it would be unfair to assess their performance based on the success rate of operations as there were complicated clinical factors involved. Doctors who took on more difficult operations might end up with a lower success rate and they were likely to avoid hard cases (Moy, 2001b). The same concern led an HA board member to reject the idea of publishing a "league table" of surgeons' performances (Lee, 2002).

While maintaining an internal accountability system, the HA is also subject to external oversight. As already mentioned, the Audit Commission has reviewed the HA's organization and processes. Apart from its report on the purchase of medical equipment, it had earlier investigated the HA's fringe benefits for staff. It criticized the HA for paying $\$ 425$ million more to its staff than their civil service counterparts had been paid in the previous 5 years (Chan, 1995). While the Audit Commission is independent of the government, the Medical Council acts on behalf of the government to supervise professional behavior and investigate complaints (Gauld \& Gould, 2002: 96). Yet, of the 28 members in 1999, all but four were doctors. The Council meets in secret and has no power to penalize under-performing practitioners. It has thus been criticized for protecting doctors' interests (Kong, 1999). Not surprisingly, the Harvard Team also noted the problems of physician dominance, the medical profession's self-regulation, and the lack of strong checks and balances. They recommended the setting up of a special ombudsman office to handle complaints (Legislative Council, 2005: 3-5). However, the government sought to protect the autonomy of the profession and proposed instead a Patient Complaints Office which would be administrative in nature so that the investigation of complaints would remain the tasks of the PCC and the Medical Council (Lee,

\footnotetext{
${ }^{5}$ In the year 2003/2004, of the 15 members who sat on the PCC, only three were HA doctors while the other 12 came from the community (HA, 2003/2004).
} 
1999a, b). In response, the Consumer Council criticized the proposal on the grounds that the medical system was fragmented and dominated by doctors (Lee, 1999a, b).

In 2002, as part of its wider civil service reform, the government introduced the "Principal Officials Accountability System" whereby bureau secretaries would be held responsible for their policy outcomes. The following year, the SARS epidemic infected 1,755 people and 299 (including eight health workers) died. The government commissioned an Expert Committee to investigate the handling of the crisis, but the committee was unable to apportion blame. Politicians called for another investigation, this time by the Legislative Council (Lee \& Benitez, 2003b). The Legislative Council SARS Panel made several criticisms of the performance of the bureau secretary, the HA chairman, the HA chief executive and one HA director. Patient groups called on these individuals to apologize and step down (Cheung, Shamdasani, \& Wong, 2004). The secretary and the HA chairman subsequently resigned in order to "shoulder political accountability" (Cheung, 2004). While the bureau secretary was a political appointee, the HA chairman and HA chief executive were contract staff who even the chairman of the Legislative Council SARS Panel did not consider should resign although their actions had been criticized in the Council's report (Shamdasani, Chan, \& Wong, 2004). Nonetheless, community calls for them to do so and the resignation of the HA chairman demonstrated that they were subject to political pressure (Cheung et al., 2004). As the HA chief executive put it, the HA "feels helpless but we understand the political realities" (Benitez \& Moy, 2004).

The performance of a health system, according to Yuen (1991), must ultimately be assessed in terms of its outputs and outcomes, such as life expectancy at birth, infant mortality rates, cost-effectiveness and consumer satisfaction, and not in terms of its structures and processes. Against such yardsticks, the HA has performed very well. Hong Kong's life expectancy at birth for men and women ranked first and second in the world respectively in 2004 (HMDAC, 2005: 3). Client satisfaction surveys indicate the majority of Hong Kong's public are positive about the service they receive (Holliday \& Tam, 2000). OECD health data suggests that at $14 \%$ of government recurrent expenditure, health care in Hong Kong is competitive with other industrial countries (Hong Kong Budget Estimates, 2005-2006; OECD, 2005). But under new fiscal pressures, there is some doubt about whether the quality of the service provided by the HA can be maintained. The HA has recently been urged to outsource its specialist services to shorten waiting times, reduce default appointments, and eliminate operational inefficiencies (Lee \& Benitez, 2005). The legislator representing the medical sector has complained that the quality of services purchased might not be satisfactory because there was little money left to purchase services from the private sector after salaries had been paid (Wu, 2004).

The idea that performance can be measured in terms of outputs and outcomes alone and not by process is, in any event, doubtful. Recent years have witnessed increasing emphasis on due process, especially in relation to public bodies such as the HA which is responsible for the health of the community. In this sense, the HA's immunity from public scrutiny is more vice than virtue. The HA's refusal to publish clinical audit results on its surgical performance might be justified insofar as operations might be affected by external factors and because publication of audit results might unfairly ruin doctors' reputations, destroy patients' confidence, and 
tempt doctors to take on easier cases. However, the HA should at least inform the public of follow-up actions it takes to address problems as they emerge, such as preventing certain surgeons from performing specific operations, or, if they are allowed to continue, any rectification measures that have been put in place (South China Morning Post, 7 December 2002). Lastly, all the SARS panels, whether commissioned by the government, formed by the HA itself, or established by independent legislators, have exposed various weaknesses within the HA's structure and its relationships with other actors. These weaknesses can cost lives in the event of a crisis.

\section{Conclusion}

The foregoing analysis of the Hong Kong Hospital Authority tells a story of challenges and uncertainties for an organization charged with providing a major public service at arms' length from government. Responding to the needs of the time, the HA was established as a statutory corporation to allow for greater management autonomy and flexibility in the belief that this would bring improved operating efficiencies and higher quality services into public healthcare. It also provided an opportunity to bring the government and subvented hospitals into one uniform system. This is also a story of multiple actors with different and conflicting interpretations and expectations of roles and responsibilities. Statutory independence, with its promise of improved efficiency, has its limits in the highly complex field of health where there are multiple players from private as well as public sectors and where professional autonomy remains a key claim. The political salience of health care was nowhere more in evidence than during the SARS crisis.

To return to the three main questions addressed in the introduction to this article: the first asked in what aspects has the HA experienced autonomy and in what other aspects has it undergone integration? The experience of the HA has been one of shifting concepts of autonomy, when more or less is considered desirable. While the transfer of clinics from the Department of Health to the HA signified integration between these two organizations, that they gave differing advice and failed to access each other's databases during the SARS crisis exposed a lack of coordination and cooperation. Although the HA board's role is to monitor the management executives as a collective body, it left the senior management very much to themselves in their handling of SARS and further delegated the task of supervision to the chairman alone. While maintaining a tight budgetary control over staff costs, the HA head office allowed decisions on the deployment of staff to be made by individual hospitals during the SARS outbreak, leading to confusion among frontline workers. Under the cluster concept, introduced to foster patient referrals and resource sharing, hospitals shared workload among themselves while, at the same time, competing for protective equipment in the battle against SARS. Although the HA still maintained the PCC as an internal inquiry system, SARS left the HA vulnerable to political pressure which resulted in the resignation of its chairman.

The second question asked: Insofar as autonomy and integration are in tension, has the HA moved further in one direction than the other? For the last 15 years, the HA's external and internal relationships have been characterized by an interplay 
between autonomy and integration. In relation to the bureau, the HA has been vacillating between the demand for more autonomy in day-to-day operations such as the procurement of medical equipment, and integration in the form of more accountability to its parent bureau. Under budgetary pressure, the HA has gradually contracted out public clinics to the private sector, but it has also engaged in competition with private hospitals by opening more private wards. Financial decentralization led the Audit Commission to suggest strengthening the bureau's supervision over the HA's expenditure and establishing a central procurement and maintenance unit in the HA head office. After SARS, the government was urged by experts and legislators to regain control of the HA by various methods such as having the secretary act as chair of the board, to merge the department and the HA, or to have a single person serve as both chief executive and board chairman. Most recently, the 2005 consultation document further urges the HA to merge different A\&E departments and to purchase services from the private sector in an effort to stem its growing deficit. In short, attempts have been made to wrest back control from the HA after crises.

The third question asks: Has agency autonomy benefited the public? There is little doubt that Hong Kong's health service is one of the best in the world in outcome terms. The publicly funded system has been hugely popular with the community and the HA has been attributed with restoring public confidence in the health care system. However, while still remaining comparatively competitive with other industrial countries, the cost of providing the service is a concern for the government. Further, the chance event of SARS revealed many organizational and management shortcomings within the HA, raising community concerns.

Swings from autonomy to reintegration are, in part, knee-jerk reactions and reflect observations made by the Harvard Team in 1999. They claimed, rightly or wrongly, that Hong Kong did not have a coherent policy for financing or organizing health care. More telling was their observation that the government only reacted to serious problems, thus preferring incremental solutions. As has been suggested by Gauld and Gould (2002), perhaps the root of the health care "crisis" lies in the absence of a stated healthcare philosophy or consensus over how to strike the balance between values such as equity, efficiency, quality and cost control. Until such a consensus can be reached, the HA's "tango" between autonomy and integration is expected to continue.

\section{References}

Audit Commission. 2001. Chapter 10 on the Hospital Authority's management of medical equipment. Director of Audit's Report No 37. Hong Kong: The Commission.

Benitez, M. A. 2001. Senior doctor hits out over health reforms. South China Morning Post, March 26.

Benitez, M. A. 2002. Hospitals could close in shake-up, new chief warns. South China Morning Post, October 30 .

Benitez, M. A. 2003. Hospitals told not to expand private wards. South China Morning Post, March 11. Benitez, M. A., \& Moy, P. 2004. Hospitals chief issues a new apology; William Ho responds to critical letters on the Public Doctors Association website. South China Morning Post, July 14.

Chan, Q. 1995. Sir SY in attack on auditor over perks. South China Morning Post, December 7.

Chan, Q. 1999. Patients promised better system for handling gripes. South China Morning Post, July 10. Cheung, A. 2003. A caring profession or a cold business? South China Morning Post, June 11. 
Cheung, J. 2004. Criticisms of health officials over SARS unfair, says scientist. South China Morning Post, July 12.

Cheung, G., Shamdasani, R., \& Wong, M. 2004. Victims say more heads should roll over virus; For many, the resignations tendered so far do not go far enough. South China Morning Post, July 9.

Gauld, R. 1998. The further development of the Hong Kong Hospital Authority. Asian Journal of Public Administration, 21(1): 57-78.

Gauld, R., \& Gould, D. 2002. The Hong Kong health sector: Development and change. Hong Kong: The Chinese University Press.

Hayllar, M. R. 1999. Reforms to enhance accountability and citizen involvement: A case study of the Hong Kong Hospital Authority. International Journal of Public Administration, 22(3/4): 461-498.

Health and Medical Development Advisory Committee (HMDAC). 2005. Building a healthy tomorrow. Discussion Paper on the Future Service Delivery Model for Our Health Care System, Hong Kong.

Health, Welfare and Food Bureau (HWFB). 2004. Primary health care: Current status and future development. Paper submitted to the Legislative Council Panel on Health Services, No. CB(2)3105/ 03-04(03), Hong Kong.

Holliday, I., \& Tam, W.-k. 2000. Fragmentation in the Hong Kong health care system: Myth and reality. Asian Journal of Public Administration, 22(2): 161-181.

Hon, M., Sin-m. 2001. Bureau under fire for failing to monitor fund. South China Morning Post, December 4.

Hong Kong Budget Estimates for 2005-2006. Hong Kong: The Council.

Hospital Authority. 2003/2004. Annual Report 2003-2004. Hong Kong: The Authority.

Hospital Authority. 2005. About the hospital authority-Board and Committees (Retrieved 17 August 2005 from (http://www.ha.org.hk).

Hospital Authority Review Panel on the SARS Outbreak (HA Review Panel). 2003. Report of the hospital authority review panel on the SARS outbreak. Hong Kong: The Panel.

Kong, L.-F. 1999. Doctors to consider patients' complaints; New panel will adjudicate behind closed doors. South China Morning Post, December 14.

Lam Wan, R. 1999. Competition for hospitals may hurt patients. South China Morning Post, April 19.

Lau, C. K. 2004. The buck should stop with one boss. South China Morning Post, August 12.

Lee, E. 1999a. Medical Ombudsman call. South China Morning Post, December 10.

Lee, E. 1999b. New body to deal with patients' complaints. South China Morning Post, November 5.

Lee, E. 2000a. Complaints body to hold briefings. South China Morning Post, February 4.

Lee, E. 2000b. Clinics may go private in overhaul. South China Morning Post, March 27.

Lee, E. 2002. Tread carefully with audit, surgeons warn; A league table is not the answer, say doctors, but patients want to see poorly performing hospitals called to account. South China Morning Post, December 7.

Lee, E. 2003. No warlord mentality in hospitals, says chief. South China Morning Post, May 1.

Lee, E. 2004. SARS mistakes highlight need for reform, says authority chief; Review aims to strengthen top management and create uniformity. South China Morning Post, February 26.

Lee, E., \& Benitez, M. A. 2003a. Rein in the Hospital Authority, say critics. South China Morning Post, October 27.

Lee, E., \& Benitez, M. A. 2003b. SARS report 'will not single out any officials for blame'; Calls grow for Legco inquiry as sources say panel backpedals on naming names. South China Morning Post, October 1 .

Lee, E., \& Benitez, M. A. 2005. Patients prepared to pay to cut queues for specialist services, survey shows. South China Morning Post, June 1.

Legislative Council Secretariat. 2005. Health care reform. Paper submitted to the Panel on Health Service, LC Paper No CB(2)2252/04-05(01), Hong Kong.

Legislative Council Select Committee to Inquire into the Handling of the Severe Acute Respiratory Syndrome Outbreak by the Government and the Hospital Authority. 2004. Report of the Legislative Council Select Committee to Inquire into the Handling of the Severe Acute Respiratory Syndrome Outbreak by the Government and the Hospital Authority. Hong Kong: The Council.

Moir, J. 1997. Medical complaints body may be revamped. South China Morning Post, November 25.

Moy, P. 2001a. Outside auditors to monitor surgeons. South China Morning Post, June 26.

Moy, P. 2001b. Doctors worried over audit fairness. South China Morning Post, June 26.

Moy, P., \& Lee, K. 2003. Hospitals told to end warlord mentality; Uncooperative attitudes may be undermining the anti-SARS fight, say critics. South China Morning Post, April 29.

Organisation for Economic Cooperation and Development. 2005. Health at a Glance: OECD Indicators 2005. Paris: OECD. 
Parwani, A., \& Lam Wan, R. 1999. Scrapping of authority labeled too drastic. South China Morning Post, April 13.

Pollitt, C. 1986. Beyond the managerial model: The case for broadening performance assessment in government and public services. Financial Accountability and Management, 2(3): 155-170.

SARS Expert Committee. 2003. SARS in Hong Kong: From experience to action. Hong Kong: The Committee.

Scott, I. 2005. Public administration in Hong Kong: Regime change and its impact on the public sector. Singapore: Marshall Cavendish International.

Scott Report (Coopers and Lybrand/WD Scott). 1985. The delivery of medical services in hospitals: A report for the Hong Kong government. Hong Kong.

Shamdasani, R., Chan, C., \& Wong, M. 2004. If hospital chief quits we'll go too, board threatens. South China Morning Post, July 8.

South China Morning Post. 1993. New system streamlines health care. Supplement, January 7.

South China Morning Post. 2002. Show us the care for surgical woes. Editorial, December 7.

Tacey, E. 1996. Drug cost cuts hit patient care, doctors claim. South China Morning Post, 20 August.

Thompson, D., Snape, E., \& Stokes, C. 1999. Health services reform and human resource management in Hong Kong public hospitals. International Journal of Health Planning and Management, 14: 19-39.

Thynne, I., \& Wettenhall, R. 2004. Public management and organizational autonomy: The continuing relevance of significant earlier knowledge. International Review of Administrative Sciences, 70(4): 609-621.

Wan, M. 1993. Plan to cut waiting lists at HA clinics. South China Morning Post, November 14.

Wiseman, A. 1995. Hospital woes hit eye care. South China Morning Post, March 7.

Wu, E. 2004. Outsourcing clinics 'would hurt services.' South China Morning Post, May 18.

Yeoh, E. 2001. Speech at the First National Disease Management Conference co-organized by the National HealthCare Group, the Disease Management Association of America and the Ministry of Health in Singapore, May 25.

Yuen, P. 1991. The implications of the corporatization of health care delivery in Hong Kong. Asian Journal of Public Administration, 13(1): 23-38.

Yuen, P. 1994. The corporatization of public hospital services in Hong Kong: A possible public choice explanation. Asian Journal of Public Administration, 16(2): 165-181. 